\title{
Memodelkan Pendapatan Asli Daerah Kabupaten Kota di Jawa Tengah
}

\section{Modeling Regency Regional Original Revenue in Central Java}

Raras Kinanthi ${ }^{1}$, Abdul Hakim ${ }^{1 *}$

${ }^{1)}$ Department of Economics, Universitas Islam Indonesia

\begin{abstract}
This paper models District Revenue (DR) in regencies and cities in Central Java. The independent variables that are expected to describe the DR behavior are Gross Regional Per Capita Income (GRPCI), Population (POP), Regional Government Expenditure (GOV), and inflation (INF). The panel data covers 35 regencies and cities in Central Java, from 2012 to 2016. Using the regression model of panel data with fixed effect method, it is found that all the variables significantly influence DR with inflation as the dominant variable followed by the population. Government expenditures, the vairable that can be controlled directly by the government, have only the smallest influence among the other four variables.
\end{abstract}

Keywords: district Revenue, panel data, government expenditure

JEL classification number: $H 72, H 73$

\section{ABSTRAK}

Penelitian ini memodelkan Pendapatan Asli Daerah (PAD) di Kabupaten dan Kota di Jawa Tengah. Variabel independen yang diharapkan bisa menggambarkan perilaku PAD tersebut adalah Pendapatan Regional Bruto Perkapita (PDRBP), Junlah Penduduk (POP), Pengeluaran Pemerintah Daerah (GOV), serta inflasi (INF). Data panel meliputi 35 kabupaten dan kota di Jawa Tengah, dari tahun 2012 sampai dengan 2016. Dengan menggunakan model regresi data panel dengan metode fixed effect, didapatkan bahwa semua variabel berpengaruh signifikan dengan inflasi sebagai variabel dominan diikuti oleh jumlah penduduk. Pengeluaran pemerintah, variabel yang bisa dikontrol langsung oleh pemerintah, hanya memiliki pengaruh terkecil di antara empat variabel yang lain.

Kata Kunci: Pendapatan Asli Daerah, data panel, pengeluaran pemerintah JEL classification number: $\mathrm{H} 72, \mathrm{H} 73$ 


\section{PENDAHULUAN}

Indonesia adalah sebuah negara besar, memiliki 34 provinsi dan ribuan pulau. Dengan kondisi tersebut, tampaknya otonomi daerah merupakan pilihan sistem pemerintahan yang tepat, meskipun tidak semua peneliti sepakat akan hal ini (Jati 2012). Pelaksanaan otonomi daerah ini menuntut daerah untuk bisa mengelola daerahnya sendiri, dan untuk itu diperlukan dana yang memadai. Menurut UU No. 33 Tahun 2004, sumber pendanaan pemerintah daerah dalam pelaksanaan desentralisasi meliputi Pendapatan Asli Daerah (PAD), Dana Alokasi Umum (DAU), Dana Alokasi Khusus (DAK), Dana Bagi Hasil (DBH), Pinjaman Daerah, dan lain-lain. Terdapat variasi sumber-sumber penerimaan antar daerah. Sumber penerimaan daerah saat ini didominasi oleh bantuan pemerintah pusat dalam bentuk DAU, DAK, dan Dana Bagi Hasil, sedangkan proporsi PAD masih relatif kecil (Soleh dan Rochmansjah 2010).

Provinsi Jawa Tengah terdiri dari enam Kota dan 29 Kabupaten. PAD di Jawa Tengah mengalami trend positif dari 2010 sampai 2016. Namun demikian, peningkatan tersebut tidak memberikan dampak yang cukup signifikan terhadap upaya menuju kemandirian daerah. Mengingat arti penting PAD yang bukan hanya sebagai pelengkap sumber dana pembangunan jangka pendek, tetapi juga merupakan sumber ideal jangka panjang, maka diperlukan sebuah model yang bisa menggambarkan perilaku empiris PAD tersebut. Penelitian ini mencoba membangun model tersebut. Penelitian ini mengambil kasus di Kabupaten dan Daerah Kota di Provinsi Jawa Tengah.

\section{METODOLOGI}

Penelitian menggunakan data panel di 35 Kabupaten dan Kota di Provinsi Jawa Tengah periode 2012-2016. Data terseut diperoleh dari Badan Pusat Statistik. Variabel independen yang digunakan adalah PDRB perkapita, jumlah penduduk, jumlah pengeluaran pemerintah, dan inflasi. Data panel digunakan karena memiliki berbagai kelebihan, terutama dalam proses pengujian signifikansi variabel. Hal ini bersumber dari ukuran sampel yang membesar sehingga derajat bebas meningkat, yang pada akhirnya menurunkan nilai kritis sehingga lebih mudah untuk menolak Ho bahwa variabel independen yang dipilih menjadi signifikan. Untuk diskusi lebih jauh tentang keunggulan model data panel (Hsiao 2007).

Variabel dependen yang dimodelkan adalah Pendapatan Asli Daerah (PAD). PAD adalah semua penerimaan daerah yang diakui sebagai penambahan kekayaan bersih dari sumber ekonomi asli Kota dan Kabupaten provinsi Jawa Tengah dan dihitung dengan juta rupiah. Menurut Undang-Undang Nomor 33 Tahun 2004 tentang Perimbangan Keuangan Antara Pusat dan Daerah Pasal 1 angka 18, PAD adalah pendapatan yang diperoleh daerah yang dipungut berdasarkan peraturan daerah sesuai dengan peraturan perundang-undangan.

Variabel-variabel independen yang dimasukkan adalah PDRB perkapita, yakni nilai produksi dari pendapatan setiap jumlah penduduk yang diperoleh dari jumlah PDRB dibagi jumlah penduduk, yang bisa sebagai gambaran Daya Beli Masyarakat di Kabupaten dan Kota di Provinsi Jawa Tengah dan dihitung ribu Rupiah. Jumlah Penduduk, didefinisikan sebagai penghuni atau merupakan semua orang yang mendiami wilayah Kota dan Kabupaten provinsi Jawa Tengah dan dihitung per jiwa. Pengeluaran Pemerintah, merupakan salah satu aspek penggunaan sumber daya ekonomi yang secara langsung dikuasai pemerintah dan secara tidak langsung dimiliki oleh masyarakat melalui pembayaran pajak di kota dan kabupaten Provinsi Jawa Tengah yang diukur dengan juta rupiah. Inflasi adalah kejadian apabila tingkat harga-harga dan biaya-biaya umum di Kota dan Kabupaten provinsi Jawa Tengah naik secara terus-menerus dalam jangka panjang yang diukur dengan persentase.

Kandidat utama variabel penentu PAD adalah jumlah penduduk (Santoso dan Retno 2005

Jurnal Manajemen dan Organisasi (JMO),

Vol. 9 No. 2 , Agustus 2018, Hal. 74-80 dan Veronica et al. 2016). Anggaran belanja pembangunan yang dialokasikan pada program proyek yang langsung menyentuh sektor ekonomi produktif masyarakat juga dianggap bisa meningkatkan perekonomian masyarakat (Veronica et al. 2016). Dalam mendukung pembangunan, pemerintah membutuhkan berbagai sarana dan fasilitas pendukung, termasuk anggaran belanja. Belanja tersebut bisa meningkatkan pengeluaran agregat dan meningkatkan 
tingkat kegiatan ekonomi. Dengan meningkatnya kegiatan ekonomi, maka aliran penerimaan pemerintah melalui PAD akan meningkat. Meskipun demikian, tidak semua peneliti memiliki pendapat yang sama. Sriyana dan Hakim (2014) menemukan bahwa peningkatan belanja pemerintah tidak menjamin munculnya sumber bagi penerimaan pemerintah.

Inflasi menimbulkan beberapa efek buruk pada perekonomian, di antaranya mengurangi pendapatan riil masyarakat (Braumann 2001 dan Bozkurt 2014). Tetapi dengan adanya inflasi, maka upah dan gaji nominal juga naik. Ketika inflasi melambat perusahaan akan sedikit menaikkan harga produk setiap tahun, yang mengakibatkan pendapatan pengusaha lebih besar dan akan memberi para pekerja kenaikan upah yang lebih kecil. Dalam hal ini pemerintah mengenakan pajak untuk menaikkan potensi penerimaan daerah. PDRB dan pajak daerah sebagai variabel yang mempengaruhi PAD sudah ditemukan oleh Veronica et al. (2016), dan digunakan sebagai variabel control dalam penelitian ini.

Alat analisis yang digunakan adalah model regresi data panel dengan menggunakan aplikasi Eviews 8. Penelitian ini menggunakan analisis data panel 2012-2016, terdiri dari 35 kabupaten dan kota di Provinsi Jawa Tengah. Model fungsi yang digunakan untuk melihat Pendapatan Asli Daerah di Provinsi Jawa Tengah yaitu:

$$
\mathrm{LY}_{\mathrm{it}}=\beta_{0}+\beta_{1} \mathrm{LPDRBP}_{\mathrm{it}}+\beta_{2} \mathrm{LPOP}_{\mathrm{it}}+\beta_{3} \mathrm{LGOV}_{\text {it }}+\beta_{4} \mathrm{LINF}_{\text {it }}+\mathrm{u}_{\mathrm{it}}
$$

Dimana $L$ adalah operator untuk $\ln , Y$ adalah Pendapatan Asli Daerah (Juta Rupiah); PDRBP adalah Produk Domestik Regional Bruto perkapita (Ribu Rupiah); POP adalah jumlah penduduk (jiwa); GOV pengeluaran pemerintah (juta Rupiah), INF adalah inflasi (\%), $i$ adalah operator untuk cross section, dan $t$ adalah operator untuk time-series.

Dalam mengestimasi regresi data panel, terdapat tiga macam pendeketan yang dapat digunakan, yaitu Common Effect Models, Fixed Effect Models, dan Random Effect Models. Model Common Effect berasumsi bahwa intersep dan slope adalah tetap sepanjang waktu dan individu. Model Common Effect bisa ditulis sebagai berikut:

$$
\mathrm{Y}_{\mathrm{it}}=\beta_{0}+\sum_{\mathrm{n}=1}^{\mathrm{n}} \beta_{\mathrm{k}} \mathrm{X}_{\mathrm{kit}}+\varepsilon_{\mathrm{it}}
$$

Model Fixed Effect mengakomodasi kemungkinan intersep yang berbeda-beda untuk setiap subjek (cross section), tetapi slope setiap subjek tidak berubah seiring waktu. Model Common Effect bisa ditulis sebagai berikut:

$$
\mathrm{Y}_{\mathrm{it}}=\beta_{\mathrm{i}}+\sum_{\mathrm{n}=1}^{\mathrm{n}} \beta_{\mathrm{k}} \mathrm{X}_{\mathrm{kit}}+\varepsilon_{\mathrm{it}}
$$

Model Random Effect merupakan alternatif solusi jika model Fixed Effect tidak tepat. Metode ini memilih estimasi data panel dengan residual yang mungkin saling berhubungan antar waktu dan individu, dengan mengasumsikan setiap objek mempunyai intersep. Namun diasumsikan bahwa intersep adalah variabel random. Persaman sistematis untuk model Random Effect yaitu:

$$
\mathrm{Y}_{\mathrm{it}}=\beta_{1 \mathrm{i}}+\sum_{\mathrm{n}=1}^{\mathrm{n}} \beta_{\mathrm{k}} \mathrm{X}_{\mathrm{kit}}+\varepsilon_{\mathrm{it}}
$$

Dimana $\beta_{1 i}$ adalah sebuah variabel random dengan nilai rata-rata $\beta_{1}$, dan intersep dari kabupaten atau kota individual bisa dinyatakan sebagai $\beta_{1 \mathrm{i}}=\beta_{1}+\varepsilon_{i} i=1,2, \ldots, \mathrm{N}$, dimana $\varepsilon_{i}$ adalah error term yang random dengan mean nol dan variance $\sigma_{\varepsilon}^{2}$.

Untuk memilih model yang tepat, dilakukan dua tahap pengujian. Uji pertama adalah uji Chow (Uji F) untuk membandingkan antara metode Fixed Effect dengan Common Effect. Dari uji pertama ini, jika model Fixed Effect terpilih, maka dilakukan uji kedua, yakni uji Haussman, yaitu untuk membandingkan antara metode Fixed Effect dengan Random Effect. 


\section{HASIL DAN PEMBAHASAN}

Hasil Estimasi menggunakan model Common Effect disajikan pada Tabel 1.

Tabel 1. Hasil regresi Common Effect Model

\begin{tabular}{lccc}
\hline \multicolumn{1}{c}{ Variable } & Coefficient & t-Statistic & Prob. \\
\hline C & $-2.18 \mathrm{E}+08$ & -7.877387 & 0.0000 \\
PDRBP? & 4.986555 & 10.14334 & 0.0000 \\
POP? & 12.12530 & 0.405160 & 0.6859 \\
GOV? & 0.192162 & 9.275820 & 0.0000 \\
INF? & -3358930. & -1.252409 & 0.2121 \\
\hline R-squared & 0.731050 & F-statistic & 115.5222 \\
Adjusted R-squared & 0.724722 & Prob $($ F-statistic $)$ & 0.000000 \\
\hline
\end{tabular}

Hasil output pada regresi menggunakan Fixed Effect Model ditunjukan dalam Tabel 2.

Tabel 2. Hasil regresi Fixed Effect Model

\begin{tabular}{|c|c|c|c|}
\hline Variable & Coefficient & $t$-Statistic & Prob. \\
\hline $\mathrm{C}$ & $-2.35 \mathrm{E}+09$ & -8.095588 & 0.0000 \\
\hline PDRBP? & 8.869943 & 6.322724 & 0.0000 \\
\hline POP? & 2286.204 & 6.978247 & 0.0000 \\
\hline GOV? & 0.091815 & 8.098447 & 0.0000 \\
\hline INF? & 1965731. & 1.841740 & 0.0677 \\
\hline Fixed Effects (Cross) & & Fixed Effects (Cross) & \\
\hline _CILACAP--C & $-1.58 \mathrm{E}+09$ & _KUDUS--C & $-1.64 \mathrm{E}+08$ \\
\hline _BANYUMAS--C & $-1.38 \mathrm{E}+09$ & JEPARA--C & $-4.19 \mathrm{E}+08$ \\
\hline _PURBALINGGA--C & $2.14 \mathrm{E}+08$ & _DEMAK--C & $-2.66 \mathrm{E}+08$ \\
\hline _BANJARNEGARA--C & $1.44 \mathrm{E}+08$ & _SEMARANG--C & -76585670 \\
\hline KEBUMEN--C & $-5.00 \mathrm{E}+08$ & _TEMANGGUNG--C & $5.38 \mathrm{E}+08$ \\
\hline _PURWOREJO--C & $5.99 \mathrm{E}+08$ & _KENDAL--C & 10862383 \\
\hline _WONOSOBO--C & $4.34 \mathrm{E}+08$ & BATANG--C & $5.46 \mathrm{E}+08$ \\
\hline _MAGELANG--C & $-5.80 \mathrm{E}+08$ & _PEKALONGAN--C & $3.15 \mathrm{E}+08$ \\
\hline _BOYOLALI--C & 1155100 & _PEMALANG--C & $-6.94 \mathrm{E}+08$ \\
\hline _KLATEN--C & $-4.93 \mathrm{E}+08$ & _TEGAL-C & $-1.01 \mathrm{E}+09$ \\
\hline _SUKOHARJO--C & $2.58 \mathrm{E}+08$ & _BREBES--C & $-1.85 \mathrm{E}+09$ \\
\hline _WONOGIRI--C & 15928568 & _KOTAMAGELANG--C & $1.76 \mathrm{E}+09$ \\
\hline _KARANGANYAR--C & $2.12 \mathrm{E}+08$ & _KOTASURAKARTA--C & $8.86 \mathrm{E}+08$ \\
\hline SRAGEN--C & $1.70 \mathrm{E}+08$ & _KOTASALATIGA--C & $1.56 \mathrm{E}+09$ \\
\hline GROBOGAN--C & $-8.25 \mathrm{E}+08$ & _KOTASEMARANG--C & $-1.38 \mathrm{E}+09$ \\
\hline BLORA--C & $2.45 \mathrm{E}+08$ & _KOTAPEKALONGAN--C & $1.52 \mathrm{E}+09$ \\
\hline _REMBANG--C & $8.22 \mathrm{E}+08$ & _KOTATEGAL--C & $1.55 \mathrm{E}+09$ \\
\hline PATI--C & $-5.91 \mathrm{E}+08$ & & \\
\hline$R$-squared & 0.972130 & $F$-statistic & 124.8356 \\
\hline Adjusted $R$-squared & 0.964342 & $\operatorname{Prob}(F$-statistic) & 0.000000 \\
\hline
\end{tabular}

Hasil output pada regresi menggunakan metode Fixed Effect ditunjukan dalam Tabel 3.

Tabel 3. Hasil regresi Random Effect Model

\begin{tabular}{|c|c|c|c|}
\hline Variable & Coefficient & $t$-Statistic & Prob. \\
\hline $\mathrm{C}$ & $-3.43 \mathrm{E}+08$ & -8.148997 & 0,0000 \\
\hline PDRBP? & 8.312004 & 11.13751 & 0,0000 \\
\hline POP? & 118.4044 & 3.178660 & 0,0018 \\
\hline GOV? & 0.150517 & 16.60149 & 0,0000 \\
\hline INF? & -1241350 & -1.243281 & 0,2155 \\
\hline
\end{tabular}




\begin{tabular}{|c|c|c|c|}
\hline Fixed Effects (Cross) & \multicolumn{3}{|c|}{ Fixed Effects (Cross) } \\
\hline CILACAP--C & -36915285 & KUDUS--C & $-4.20 \mathrm{E}+08$ \\
\hline _BANYUMAS--C & 6733549 & _JEPARA--C & 38333048 \\
\hline PURBALINGGA--C & 71930037 & _DEMAK--C & 49156824 \\
\hline BANJARNEGARA--C & 11067771 & SEMARANG--C & -4444496. \\
\hline _KEBUMEN--C & -38757531 & _TEMANGGUNG--C & 73949581 \\
\hline _PURWOREJO--C & 56981803 & _KENDAL--C & -32636069 \\
\hline _WONOSOBO--C & 48917801 & _BATANG--C & 80633865 \\
\hline MAGELANG--C & 636435.0 & _PEKALONGAN--C & $1.30 \mathrm{E}+08$ \\
\hline _BOYOLALI--C & -3183374 & _PEMALANG--C & -577628.3 \\
\hline _KLATEN--C & -87989152 & _TEGAL--C & -25913741 \\
\hline _SUKOHARJO--C & 41016062 & BREBES--C & $-1.18 \mathrm{E}+08$ \\
\hline _WONOGIRI--C & -21999147 & _KOTAMAGELANG--C & 8553778 \\
\hline KARANGANYAR--C & -28978023 & _KOTASURAKARTA--C & -61661057 \\
\hline SRAGEN--C & -14113053 & _KOTASALATIGA--C & -55841335 \\
\hline GROBOGAN--C & -3476062 & KOTASEMARANG--C & $1.04 \mathrm{E}+08$ \\
\hline BLORA--C & 4898281. & _KOTAPEKALONGAN--C & $1.27 \mathrm{E}+08$ \\
\hline _REMBANG--C & 84217221 & _KOTATEGAL--C & 52489785 \\
\hline PATI--C & -35671630 & & \\
\hline$R$-squared & 0,777187 & $F$-statistic & 148,2426 \\
\hline Adjusted $R$-squared & 0,771944 & $\operatorname{Prob}(F$-statistic) & 0,000000 \\
\hline
\end{tabular}

Untuk memilih model paling layak antara Common Effect Models vs Fixed Effect Models, maka pengujian terhadap hipotesis:

Ho: Common Efect Models lebih layak

Ha: Fixed Effect Models lebih layak

Uji ini dilakukan dengan membandingkan nilai probabilitasnya dengan alfa $=1 \%$. Jika nilai probabilitsnya lebih kecil dari alfa, maka menolak Ho berarti model yang paling layak yaitu Fixed Effect Models. Sebaliknya jika nilai probabilitas lebih besar dari alfa $1 \%$ maka menerima Ho berarti model yang paling layak yaitu Common Effect Models. Hasil uji tersaji pada Tabel 4 sebagai berikut:

Tabel 4. Uji chow

Redundant Fixed Effects Tests

Pool: FIXED

Test cross-section fixed effects

\begin{tabular}{lrrr}
\hline \multicolumn{1}{c}{ Effects Test } & Statistic & d.f. & Prob. \\
\hline Cross-section F & 34,600213 & $(34,136)$ & 0,0000 \\
Cross-section Chi-square & 396,718603 & 34 & 0,0000 \\
\hline
\end{tabular}

Dari hasil Uji F diatas dapat dilihat nilai statistic Chi-square sebesar 396.718503 dengan probilitas sebesar 0.0000 yang signifikan dalam alfa 1\%, artinya secara statistic Ho ditolak dan menerima Ha, maka model yang sesuai adalah model Fixed Effect.

Tahap kedua adalah melakukan uji Haussman. Hipotesis disusun sebagai berikut:

Ho: Random Efect Models lebih layak

Ha: Fixed Effect Models lebih layak

Tabel 5. Uji Hausman

Correlated Random Effects - Hausman Test

Pool: RANDOM

Test cross-section random effects

\begin{tabular}{cccc}
\hline Test Summary & Chi-Sq. Statistic & Chi-Sq. d.f. & Prob. \\
\hline Cross-section random & 76,854843 & 4 & 0,0000
\end{tabular}


Dari hasil uji Hausman diatas dapat dilihat nilai statistic Chi-square sebesar 76,854843 dengan probabilitas sebesar 0,0000 yang signifikan dalam alfa $1 \%$, artinya secara statistik Ho ditolak dan menerima Ha, maka model yang paling layak digunakan yaitu Fixed Effect Models. Lebih jauh, untuk menguji kelayakan model, dilakukan overall test atas model Fixed Effect yang telah terpilih. Hasil uji menunjukan bahwa probabilitas F-statistic adalah 0,0000, dengan demikian dapat kita simpulkan bahwa semua variabel independen yang dimasukkan ke dalam model mampu menggambarkan perilaku variabel dependen.

Hasil estimasi model fixed effect tampak bahwa semua variabel berpengaruh signifikan terhadap variabel dependen pada tingkat signifikansi 5\%, kecuali inflasi yang signifikan pada tingkat signifikansi 7\%. Pengaruh didominasi oleh inflasi, disusul oleh populasi, PDRB, dan GOV. tampak bahwa GOV, yang merupakan satu-satunya variabel yang bisa dikontrol langsung oleh pemerintah, justru memiliki pengaruh paling kecil terhadap PAD. Dengan demikian, harus disadari bahwa pengingkatan PAD memang merupakan tugas yang tidak ringan. PDRB perkapita bisa ditingkatkan oleh pemerintah dengan berbagai kebijakan. Populasi memiliki hubungan positif dengan PAD, sehingga pertumbuhan populasi di Jawa Tengah akan berdampak positif terhadap PAD. Karena Inflasi berpengaruh positif terhadap PAD, maka inflasi di Jawa Tengah juga membawa berkah. Namun disadari oleh semua pihak bahwa inflasi tinggi merupakan penanda bahwa masyarakat kehilangan sebagian dari daya belinya.

Signifikansi pengaruh PDRB terhadap PAD telah dianjurkan oleh beberapa penelitian. Pengaruh positif disarankan oleh Setianingsih (2017), Mujab (2017), Santoso dan Rahayu (2005) dan Aryanti dan Indarti (2010), sementara pengaruh negatif disarankan oleh Triani dan Kuntari (2010). Secara umum, saran ini searah dengan hasil dari penelitian ini. Dengan demikian, upaya peningkatan PAD bisa dilakukan dengan upaya peningkatan PDRB.

Signifikansi pengaruh jumlah penduduk terhadap PAD telah dianjurkan oleh beberapa penelitian. Pengaruh positif disarankan oleh Aryanti dan Indarti (2010), Santoso dan Rahayu (2005). Saran ini searah dengan hasil dari penelitian ini. Paling tiddak, jika jumlah penduduk meningkat, PAD juga akan meningkat sehingga bisa menyelesaikan sebagian masalah yang muncul dari pertumbuhan populasi.

Signifikansi pengaruh pengeluaran pemerintah terhadap PAD telah dianjurkan oleh beberapa penelitian. Pengaruh positif disarankan oleh Sitaniapessy (2013), Veronica et al. (2016), mendukung temuan dalam penelitian ini. Bisa disimpulkan bahwa pengeluaran pemerintah bisa dijadikan instrumen kebijakan untuk meningkatkan PAD di Jawa Tengah.

Pengaruh negatif inflasi terhadap PAD dianjurkan oleh Triani dan Kuntari (2010), sementara kebanyakan peneliti menyarankan ketiadaan pengaruh inflasi terhadap PAD (Aryanti dan Indarti 2010 dan Norrohman 2010). Hal ini berbeda dengan hasil dari penelitian ini yang menyarankan pengaruh positif dari inflasi terhadap PAD (meskipun hanya signifikan pada taraf 7\%). Seperti dikemukakan di awal, inflasi meningkatkan upah dan gaji nominal. Inflasi juga memotivasi perusahaan menaikkan harga produk setiap tahun, yang mengakibatkan pendapatan pengusaha meningkat. Hal ini bisa menjadi penyebab kenaikan PAD.

Dari hasil analisis konstanta intersep, bisa dilihat bahwa PAD tertinggi terdapat di Kabupaten Cilacap, Kabupaten Brebes dan Kota Semarang. PAD menengah terdapat di Kabupaten Pati, Kabupaten Jepara dan Kabupaten Magelang. PAD terendah terdapat di Kota Magelang dan Kota Salatiga.

\section{KESIMPULAN}

Penelitian ini memodelkan perilaku empiris PAD di Jawa Tengah dalam tingkat kabupaten/kota. Dengan menggunakan data panel didapatkan kesimpulan bahwa variabel terpilih semuanya mempengaruhi PAD dengan signifikan. Namun variabel GOV hanya memiliki peran terkecil dibandingkan variabel-variabel yang lain, sedangkan GOV merupakan variabel yang bisa dipengaruhi secara langsung oleh pemerintah. Namun demikian, PDRB perkapita berpengaruh positif terhadap PAD, sehingga upaya meningkatkan PDRB berarti upaya meningkatkan PAD. Demikian juga, jumlah penduduk berpengaruh positif terhadap PAD, sehingga peningkatan 
jumlah penduduk di Jawa Tengah bukanlah hal buruk semata-mata. Terakhir, inflasi juga berpengauh positif terhadap PAD, sehingga inflasi yang terjadi juga membawa berkah terhadap peningkatan $\mathrm{PAD}$.

Penelitian ini akan menjadi lebih baik jika tersedia data time series lebih panjang, sehingga penggunaan model panel dinamis yang mengakomodasi isu-isu time series seperti isu stasioneritas dan isu dinamis bisa diaplikasikan. Dengan demikian, disarankan kepada pihak penyedia data agar menjaga data yang sudah ada dan terus mempublikasikan data-data tersebut di masa yang akan datang.

\section{DAFTAR PUSTAKA}

Aryanti E, I Indarti. 2010. Pengaruh Variabel Makro Terhadap Pendapatan Asli Daerah Periode 2000-2009 di Kota Semarang. ASET, Jurnal Ilmu Ekonomi, 28(2), 133-151.

Bozkurt C. 2014. Money, Inflation and Growth Relationship: The Turkish Case. International Journal of Economics and Financial Issues, 4(2), 309-322.

Braumann B. 2001. "High Inflation and Real Wages," IMF Working Paper, WP/01/50. Can be downloaded from https://www.imf.org/external/pubs/ft/wp/2001/wp0150.pdf.

Hidayat T, Subagyo, AMS Asih. 2008. Pembuatan Model Penerimaan Pendapatan Asli Daerah (PAD) dengan Pendekatan system Dinamik. Prosiding Seminar Nasional Manajemen Teknologi VIII, Program Studi MMT-ITS, Surabaya 2 Agustus 2008.

Hsiao C. 2007. Benefits and Limitations of Panel Data. Econometric Reviews. 4(1), 121-174.

Jati WR. 2012. Inkonsistensi Paradigma Otonomi Daerah di Indonesia: Dilema Sentralisasi atau Desentralisasi. Jurnal Konstitusi. 9(4), 743-770.

Mujab H. 2017. Pengaruh Produk Domestik Regional Bruto, Jimlah Penduduk, Dana Alokasi Umum, dan Pengeluaran Pemerintah terhadap Pendapatan Asli Daerah Kabupaten/Kota di Provinsi Bengkulu Tahun 2010-2014, Skripsi, State Islamic University Sunan Kalijaga, Yogyakarta.

Norrohman A. 2010. Analisis Faktorfaktor yang Mempengaruhi Penerimaan Pajak Daerah di Kota Surakarta, Skripsi, Fakultas Ekonomi, Universitas Sebelas Maret.

Santoso PB, RP Rahayu. 2005. Analisis Pendapatan Asli Daerah (PAD) dan Faktor-Faktor yang Mempengaruhinya dalam Upaya Pelaksanaan Otonomi Daerah di Kabupaten Kediri. Jurnal Dinamika Pembangunan. 2(1), 9-18.

Setianingsih W. 2017. Pengaruh Peningkatan Produk Domestik Regional Bruto (PDRB) terhadap PEndapatan Asli Daerah (PAD) Kota Jambi. Fakultas Ekonomi dan Bisnis. Universitas Jambi Kampus Sorolangun.

Sholeh C, H Rochmansjah. 2010. Pengelolaan Keuangan dan Aset Daerah Sebuah Pendekatan Struktural Menuju Tata Kelola Pemerintahan yang Baik. Bandung (ID): Fokusmedia.

Sitaniapessy HAP. 2013. Pengaruh Pengeluaran Pemerintah terhadap PDRB dan PAD. Jurnal Ekonomia. 9(1), 38-51.

Sriyana J, A Hakim. 2014. Dichotomy between Decentralization and Local Government Revenue: An Empirical Analysis for Indonesia. International Journal of Economic Research. 11(3), 589-599.

Triani, Y Kuntari. 2010. "Pengaruh variabel Makro Terhadap Pendapatan Asli Daerah (PAD) Periode 2003-2007 di kabupaten Karanganyar," ASET, Jurnal Ilmu Ekonomi, 12(1), 8794.

Veronica DH, Yasin, T Widiharih. 2016. Pemodelan Pendapatan Asli Daerah (PAD) di Kabupaten dan Kota Jawa Tengah Menggunakan Geographically Weighted Ridge Regression. Jurnal Gaussian. 5(3), 383-393. 